\title{
The wood requires orthogonal cutting
}

Karol Vasilko, Dr.h.c., prof., MSc., Sc.D. Faculty of Manufacturing Technologies, Technical University of Košice, Bayerova 1, 08001 Prešov, Slovak Republic, E-mail: karol.vasilko@tuke.sk

This paper deals with problems about the wood requires orthogonal cutting and its history and presents development.

Keywords: Parameter $\mathrm{R}_{\mathrm{z}}$, turning, wood

\section{References}

[1] GRANOVSKIJ, G. I., GRANOVSKIJ, V. G.: Rezanije metallov. Moskva: Vy̌̌šaja škola 1985, 304 s.

[2] HOSHI, K., HOSHI, T.: On the metal cutting mechanism with the built-up edge. Mem.Fac. Engineering. Hekkaide University 12, č.3, 1969

[3] KALPAKJIAN, S.: Manufacturing engineering and technology. New York: Addison Wesley Publishing Company, 1989, pp.1999, ISBN 0-201-12849-7.

[4] WEBER, H., LOLADZE, T.N.: Grundlagen des Spanens. Berlin: VEB Verlag Technik, 1986, 255 s.

[5] FELHÖ, Cs., KUNDRÁK, J.: Surface roughness determination in turning of cylindrical surfaces. In Manufacturing Technology, vol.. 9, December 2009, pp.16-22. ISSN 1213-2489.

[6] MÁDL, J,: Design for Machining. In Manufacturing Technology, vol.. 9, December 2009, pp.81-85. ISSN 12132489.

[7] Patent SR č. 211831, VASILKO, K., PILC, J.: Klzné uloženie rotujúceho sústružníckeho noža. 21.3.1980

[8] KOCH, P.: Woodmachining process, Ronald Prss Company. New York, 1964.

[9] LISIČAN, J.: Obrábanie a delenie drevných materiálov. AS VŠL Zvolen, 1998, ISBN 85-1644-88

Reviews:

Prof. Jan Mádl, MSc., Ph.D. Prof. František Holešovský, MSc., Ph.D. 